\title{
Creativity or Coercion: Alternative Perspectives on Rights to Intellectual Property
}

\begin{abstract}
Part one of this paper considers the question of property rights in general and asks how such rights can be justified, contrasting Consequentialist with other approaches and concludes that it is impossible to avoid a broadly Consequentialist approach. Part two considers the question of intellectual property (IP) and asks how property rights justifications apply to it. The basic economics if IP is indispensable in this discussion. Finally, part three, considers IP in the light of modern technological developments. I conclude that the real dangers lie more in the specific ways government and special interests respond to this technology than from the nature of IP rights themselves.
\end{abstract}

KEY WORDS: Property rights, law and economics, Conequentialism, Utilitarianism, Intellectual Property

\section{Introduction and summary}

\section{We cannot avoid considering consequences}

My thesis is briefly as follows: Intellectual property as a category (of property in general) raises questions about the essential nature and generality of property rights, especially in light of modem technological developments. To understand this one needs to examine, first, the nature of property rights in general, and, second, the nature of intellectual property rights in particular. Such an examination turns up alternative approaches to the justification of property

Peter Lewin is a Clinical Professor of Economics at the University of Texas at Dallas, School of Management. His research and publications are varied but usually contain aspects of policy analysis. His recent work focuses on the use of knowledge by the business firm. rights. The literature can be seen to fall into two broad categories, those that are based on a consideration of the consequences of different property rights regimes (Consequentialist approaches); and those that are based on criteria said to be independent of consequences (Axiomatic approaches). Among the latter are natural-rights and contractarian approaches. I claim that, upon examination, this distinction is seen to be misleading and that ultimately all legal-ethical-moral justification-schemes have to be based on a consideration of consequences. Perceived (projected) consequences have to be evaluated in the light of ethical-moral belief systems, and there is no avoiding them.

The efficiency approach is very useful

Having established this, I do recognize that, in practical matters of social policy, it is no simple matter to either identify or evaluate the consequences of different property rights approaches. The sheer complexity and changeability of human societies has rendered all systematic approaches suspect. Included in this is the ubiquitous law-andeconomics (neoclassical) economics framework, (the Efficiency approach), which uses economic reasoning to identify and evaluate the consequences (good and bad) of various approaches to (intellectual) property. It is possible to effectively criticize this economic efficiency (also called here a Posnerian) approach by pointing to the complexity and irreducible uncertainty extant in modern dynamic societies. However, it is much easier to criticize than it is to find a better, or even a viable, alternative. I suggest that the Efficiency approach (with its acknowledged limits) is both very useful in 
understanding and evaluating property rights, and that, when stripped of its pretensions to "scientific precision," it is best understood as a necessary way to catalogue and weigh the general consequences of different configurations of (intellectual) property rights.

The efficiency approach is applied to intellectual property

I provide a general explanation of how economic reasoning uncovers the types of consequences inherent in intellectual property rights. When this information is applied to current institutional and technological realities we have an approach to policy-making that, though often unavoidably ambiguous in nature, has much to recommend it. Intellectual property rights regimes are seen to be composed of both creative and coercive elements that must be weighed in order to come to any policy decision. I conclude that the real dangers lie more in the specific ways governments and special interests respond to innovations and new technology than from the nature of intellectual property rights themselves. I conclude further that these dangers suggest that a common-law approach, based in the courts, with a minimum of legislative underpinning, may be the best we can achieve.

\section{Part one - the justification of property rights}

A large, diverse society cannot survive without property ... (Lessig, 2004, p. 28)

\section{What is the justification for property rights?}

Property rights are generally well understood and considered to be the fundamental basis on which economies are built. Without property rights markets could not exist, and without markets, production and consumption as we know it would be impossible. Yet the bedrock justification for property rights, that is, for the essential notion of private-ownership, is a matter of continual philosophical agitation. Scholars debate endlessly about the ethical underpinnings of private property.
The most common and pragmatic orientation proceeds from the observation, just made, that property rights are vital if we are to get the kind of society we want. Without property rights, people in general would be poorer and have many fewer options. Technological progress and innovation would be much inhibited. Societies would be more violent. Investment in productive capital would not take place.

Since such an orientation proceeds from identifying the likely beneficial consequences of a system of property rights, we may identify it as a Consequentialist argument. Consequentialist arguments include all kinds of Utilitarian arguments. "Utilitarian" can mean many things - from an approach that argues in terms of the straightforward utility of the members of society in the usual economic sense (see for example Resnik, 2003, pp. 323-326), to a much more abstract perspective in which "utility" is very broadly construed (such as the perspective I will support in the paper). All Consequentialist arguments must both identify and evaluate the likely consequences of the policy or system under consideration. Both positive and normative judgments are needed. Among Consequentialists, therefore, there is much room for disagreement, concerning both the likely consequences (positive disagreements) and concerning which consequences should count and what they are worth (normative disagreements). In other words, positive judgments cannot be avoided.

Many scholars have objected in principle to the whole approach. According to them one cannot (should not) judge the validity of property rights on the basis of the consequences of their existence. Property rights should flow from more fundamental "natural-rights" - inalienable and undeniable rights that humans have by virtue of what they are, like the right to "own oneself" and not be enslaved, and the right to receive the "fruits of one's labor" (one's justdesert), that is, the right to own what one produces. Ownership implies the right to dispose of what is owned, so the right to freedom of trade is but a short step from the first two basic (Lockean) principles. The rights that flow from these fundamental naturalrights do not depend on their consequences, they are categorical, deriving as they do from rights that are natural and "absolute" - they are not contingent. This natural-rights approach is a species of a Deontological orientation. Arguing from religious 
premises would be another. These are all Axiomatic approaches. Starting from certain fundamental postulated propositions, held to be valid in-and-of themselves (axioms), one then deduces from them other rights and wrongs (for example Nozick, 1977).

A third approach proceeds from the notion of "social contract," hence it is a Contractarian approach. Contractiarians approach rights on the basis of trying to discern which rights logically, or defensibly can be seen to be those, which the members of the society would agree to in principle and divorced from their own personal circumstances. Which rights must people agree to in the sense that they would benefit from them were they to be in the shoes of any other member of the society? (for example Buchanan, 1977).

Perhaps there are others, but these three approaches, and, indeed, often combinations of them, capture the most common ways in which the, matter is presented. As we shall see, upon examination they turn out to be not that different. The important point to note here is that, while all three approaches argue (or can argue) ${ }^{1}$ strongly in favor of the general inviolability of private property in principle, their differences, can and often do, result in differences in implications for the ethical status of the details of any property rights system. Most importantly for our purposes they imply differences in what might or should count as "property" - for example, whether or not non-tangible items, like intellectual property, can and/or should be considered property.

An Axiomatic argument can go either way depending on how the axioms are construed. For example, the "just-desert argument," alluded to above, can be used to justify restrictions on the copying of artistic expressions, which are seen as the "creation" of one's labor (Spooner, 1971). On the other hand, scholars have argued that artistic expressions cannot be considered property, not being scarce (of which more below), and, therefore, cannot morally be subject to such a restriction (Kinsella, 2001). Similarly, a Contractarian may support or oppose intellectual property depending on how he/she thinks it fits into the "social contract" - whether it is something that can be said to have the implicit consent of the people.

Both of these approaches claim a certain independence from contingency, they claim to be free of piecemeal and ad-hoc tinkering, which might compromise and corrupt a property rights system. Property rights are seen to rest on inviolable, abstract and general fundamental principles that can be appealed to when there is any doubt. Differences can be traced to different interpretations of those principles and not to differences about the nature of the world. In that sense these are logical arguments, not empirical ones (though every argument involving humans in the world naturally must embody some minimum empirical content, such as the general nature of human beings).

A Consequentialist, by contrast, considers this question to be a contingent one, dependent upon the empirical consequences to society. The status of IP is to be determined, not solely by a logical process, arguing from first principles to solid conclusions. Rather, the status of IP is a matter to be decided on the basis of the consequences to society that follow from its nature. A Consequentialist is thus apparently open to the charge of being unprincipled in her flexibility. For example, she inspires fear in the heart of the natural-rights believer who sees the slippery slope involved in the acceptance of ever-increasing coercive intrusions into personal freedom by the imposition of restrictions on the use of artistic products, innovations, literary works and the like, for which (in the natural-rightsbeliever's view) there can be no consequentialist justifications.

Such fears are readily understandable to all who claim to believe in freedom. More careful examination, however, would lead us to a remarkable conclusion, namely, that it is impossible to avoid being a Consequentialist while being a social philosopher. All arguments about rights end up being a species of Consequentialism broadly understood. (Because this argument, as important as it is, is peripheral to the main focus of this paper, I have relegated a more indepth discussion to an appendix). If it is true, as I shall suppose (for further explanation see the appendix) that all rights arguments come down to a species of Consequentialism, much of the force of the Deontological and Contractarian criticisms would appear to disappear. One interesting outcome of this then is that everyone is forced to play on the same playing field according to the same rules of the game - specifically, all disputants must proceed by identifying their fundamental values and their 
empirical assumptions (the consequences they envision). The argument can then be joined. About differences in fundamental values there can be no resolution. But about perceived consequences there is much that can be debated. ${ }^{2}$

\section{The efficiency method and its limitations?}

One way to identify the consequences is to use the Efficiency method. This is the most familiar and influential Consequentialist approach and it is used in the law-and-economics literature, of which the most well-known and impressive exponent is (Judge) Richard Posner - therefore henceforth the Posnerian approach. Posnerianism is based on the idea that any legal system, system of rights and laws, should ideally be based on the goal of social-wealth maximization, of achieving the largest possible value-added for society as a whole regardless of the particular distribution of that wealth, unless such distribution is itself a factor in the determination of total wealth. This is a broadly based "efficiency" approach to social policy.

The merits and limitations of this approach could be debated (see for example Stringham, 2001; Lewin, 1982). Here we simply note the following. This approach was initially motivated by economists searching long and hard for that particular concept of efficiency that is "objective" or value-free. The focus is on value-added or wealth created, regardless of the beneficiaries or losers. The idea is that by considering the size of the gains and losses (the netgains) that result from the adoption of any policy, or from the creation of any institutional framework, we get a good understanding of the consequences in order to aid our decision making. The trick is being able to identify consequences with any confidence, and for this economic theory and economic reasoning is indispensable.

The efficiency approach was first developed in the economics literature in the context of a static framework - that is a world in which change was basically non-existent - people's preferences were presumed stable and known to the policy maker, so were all methods of production and technologies. In such a world the maximization of total value is a trivial exercise in constrained maximization. Critics have suggested that in a world in which change is rapid and incessant, and in which uncertainty about preferences, production-methods and technologies abounds, the application of the efficiency method is severely compromised. Market processes are truly dynamic processes. They take place in "real time," they are evolutionary processes that are driven by the diversity of perceptions and expectations that individuals have of the value of resources and of the process itself. They are processes that are "open ended" and are never in equilibrium. They are processes that are characterized by novelty. For such processes the traditional types of efficiency assessments based on static models of resource allocation in which, the value of all resources is presumed to be known, is basically inapplicable. ${ }^{3}$ And in the context of IP and the dynamic digital-age economy, the static framework should surely be used with care.

Can one then say anything about efficiency? If one can it will have to be at another level and it will have to be analytically less precise than (though not entirely unrelated to) static criteria. It is at the level of the institutional framework that efficiency judgments will have to be made. And the efficiency judgments will not be of the very precise "scientific" kind to be found in the textbooks. Surely, our assessment and interpretation of history in the light of economic theory will be relevant. And, it seems to me impossible to interpret social and economic reality (history) without the benefit of economic theory. Though Posner may be much criticized, in the end even his critics find themselves using his methods. If we can learn anything from history perhaps it is that certain kinds of social, legal, and economic institutions are generally more conducive to the generation of value-creation and prosperity through innovation than are others.

So when an economist says that this or that policy is "efficient," what she really means is that, in her judgment, it will produce particular effects and that these effects are likely to be conducive to fostering the kind of society that is desirable, given the perceived alternatives. In making this argument she may be required to articulate in great detail why she believes this; why the policy will lead to the results she claims and why these results should be considered desirable (efficient). As explained this is a particular kind of Consequentialist argumentation. With this in mind we turn to an examination of intellectual property. 


\section{Part two - the justification of intellectual property rights}

[A] large, diverse and modern society cannot flourish without intellectual property (Lessig, 2002, 28).

The properties of intellectual property and how it differs from regular property

Intellectual property (IP) rights refer to legal property titles to forms of intangible or immaterial phenomena of value, like the structured system of words that make up a novel, or an invention, or a productive process. These titles grant their owners exclusive control over the production and sale of their physical instantiations, for example in books, in productive devices and, most recently in software-code. Legally speaking there are four types of IP, each with its own set of laws; namely, patents, copyrights, trademarks and trade-secrets. The most difficult and contentious are copyright and patents, and most of our attention will be devoted to them. ${ }^{4}$

The value of IP, like the value of all elements of the production structure, derives from the value of the goods or services they help to produce. IP is in essence valuable information and it is part of the physical capital structure of the economy. Intellectual property is intellectual capital. Conceptually the value of any intellectual capital component is thus the discounted netvalue of the revenue stream it makes possible. In more detail, from the vantage point of its creation, the value of the intellectual capital component (good) is calculated as the discounted value of its revenue stream, minus the discounted value of any costs necessary to produce that stream, less the cost of production of the item in the first place. So, for example, the value of a novel to its author can be calculated as the discounted sales revenue earned by the author over the life of the work (or until the copyright expires) to which we must add any non-pecuniary (nonmonetary) value the author receives from the conception, the process of creation and the mere presence of the book in the market place of ideas, ${ }^{5}$ less any marketing or "maintenance" costs undertaken by the author, and less the cost of time, effort and materials expended by the author to create the work. Of course, the value of the novel to the publisher would contain similar but different components as the costs and benefits are shared between publisher and author. And from the vantage point of "society" (in accordance with the efficiency approach) the value of the novel would include any costs and revenues (benefits) regardless of who expended or earned them.

In this regard intellectual capital is no different from any capital. The capital structure of an economy consists of a multitude of idiosyncratic, heterogeneous items that combine within economic organizations and through the market to produce items of value to sell to consumers. Their value depends on the revenues they are expected to earn for their owners and the costs of their creation and maintenance. That value can be appropriated by an owner who has title to them. In the absence such title, and of any subsidies or other inducements, the incentive for their creation might be much reduced. They would still be valuable to society once created. In fact, removing the title and placing them in the public-domain, (making them available for use by anyone) ${ }^{6}$ might allow for the creation of some complementary items whose creation has not been viable or possible before.

Of course, as long as the capital item in question, once created, is "physically scarce" (entails a positive opportunity cost to reproduce) removing ownership titles would create "congestion" problems as people vied for the use of this "free" resource. In consequence some sort of non-price rationing scheme would have to be used, such as waiting in line to use the resource or establishing ownership by physical force. So, the necessity to ration the use of such "scarce" items would in any case, preclude their "free" use in the creation of such complementary items. And it is this that, in one form or another, suggests that private titles and a market system is the most logical (efficient) way to organize production using scarce capital items. And it is this "scarcity" aspect of capital that makes IP different.

In the case of IP, once the capital good is created, in many cases, it can be reproduced without cost (or almost without cost) and, more important, its use does not deprive the owner or creator or anyone else 
of their ability to use it - it is "non-rivalrous" in consumption. This means that its use does not have to be rationed and there is no physical limitation on the creation of complementary resources or products. This difference has been variously used by both critics and defenders of intellectual property. ${ }^{7}$

\section{Alternative justifications for IP rights}

From a natural-rights standpoint, a number of arguments suggest that the lack of scarcity of intellectual property implies that, in fact, it is not property because something must logically (naturally) be scarce to qualify as property. Establishing a limitedtime exclusive title to an intrinsically "free" resource artificially creates scarcity - or creates artificial scarcity (Plant, 1934a, b). Furthermore, and more important, establishing restrictions on the use of this naturally free resource implies the need to compromise property rights to the use of physical property (Kinsella, 2001; Palmer, 1989 and 1990). If I own a VCR it is my property. If I decide to record a movie from the TV or from a cassette, my copy will not deprive anyone of theirs. This is true whether I decide to sell the copy I made or not. Prohibiting me, under threat of fine or incarceration, from using my VCR, my private property, as I see fit thus unreasonably deprives me of my freedom. It is a violation of my natural right to property that I legitimately own. Insofar as IP has to be embodied in physical property, all rights to IP imply the same type of illegitimate violations. Furthermore, the system cannot be saved by freedom of contract; individuals who purchase items that can be cheaply copied may be bound by a contract, conditional upon the sale, not to copy (or copy and sell) the item. This contract cannot, however, be held binding upon third parties who incidentally may come into possession of copyrighted ideas (Kinsella, 2001, p. 34).

That legal statute establishing property copyright arose and evolved historically in the context of statemonopoly protection has sometimes been seen as rendering them illegitimate. "Monopoly privilege and censorship lie at the historical roots of patent and copyright (Palmer, 1989, p. 264)." It started as a way to protect the investments and revenues of the printers of books and documents and by degrees was extended to music, art and other works with the purpose of similarly protecting other groups. "[IP] rights are creatures of the state, and not the product of an evolutionary process of interaction among interested parties that is later ratified through legal sanctions" (Palmer, 1989, p. 289). Thus, on multiple grounds, axiomatic approaches disqualify IP rights; they do not derive from real scarcity, they require violations of real property rights to physical property, and they are not evolved from private voluntary agreements. "The current system of intellectual property [is] the remnant of a system of monopoly privilege; rather than emerging spontaneously, like other property rights, as responses to scarcity; they could be seen as deliberate creations of scarcity through state action (Palmer, 1989, p. 266). ${ }^{8}$

On the other hand, some defenders of IP rights have suggested that the creators of such resources have a natural-right to their creations (the fruits of their labor) and that unauthorized use (copying) is tantamount to theft. Furthermore, some aspects of IP right have been justified as derivative from an individual's right to have his identity connected to his creation. Also, one's artistic creation has been seen by some as an extension of one's personality, thus endowing the artist with the right to control its reproduction (see, for example, Gordon, 1993; Hegel, 1976, pp. 41-42, see Resnik, 2003, p. 326).

A Consequentialist-Posnerian approach at first seems very different. It translates all gains and losses, benefits and costs, into the framework of the standard competitive model of supply and demand. This greatly simplifies and focuses the discussion. So, the lack of scarcity of IP, once produced, implies that titles allowing owners to restrict their use will result in a type of "monopoly" and therefore a social loss. The monopoly owner of the patent or copyright will charge a price for its use that is above the marginal cost of reproducing them. This means that the degree of reproduction is "socially inefficient" - there is the potential for a "Pareto" improvement, for a net social gain - gains that outweigh losses.

We can see this using some basic economic analysis. Consider the diagrams below. We consider the case of book copies, say of a popular novel. The demand curve D slopes down reflecting the relationship between the price of the book, measured on the vertical axis and the number of copies bought, measured on the horizontal axis. A higher price 
means fewer books are bought and sold. The value of the book to any consumer is the maximum price he/she is prepared to pay and the difference between this value and the actual price paid is called "consumer surplus," the gain to the consumer from competition that ensures that the price is lower that the maximum he/she would have been prepared to pay. If we assume that the competitive price is set at the level of the cost of producing as additional book, the marginal cost (MC); and if we assume further that this is a constant cost (not too unrealistic) then the total consumer surplus without any copyright protection would be the area under the demand curve above the MC where a competitive output quantity of $\mathrm{Q}_{\mathrm{C}}$ is produced. (Figure $1 \mathrm{~b}$ shows the situation of a marginal cost equal to zero).

Granting a copyright "monopoly" (see Figure 2 below) would result in fewer books being produced, $\mathrm{Q}_{\mathrm{M}}$ instead of $\mathrm{Q}_{C}$, at a higher price $\mathrm{P}_{\mathrm{M}}$ instead of $\mathrm{P}_{c}$. As a result of the IP "monopoly," there is a loss of consumer-surplus that is a deadweight-loss ( $\mathrm{L}$ in Figure 2 below) - a loss for which no compensation occurs in the economy. This represents the extra value to consumers (the consumer surplus) that they would derive (in excess of any costs) if copies were produced up to the point where the value of the marginal copy were equal to its marginal cost of production, QC, (in some cases close to zero, for example, a digital copy, Figure $2 \mathrm{~b}$ below) compared to the value of consumer surplus that would result when the owner-monopolist maximizes net revenue, at $\mathrm{Q}_{\mathrm{M}}$. (This is the point at which marginal revenue (MR) equals $\mathrm{MC}$ ).

This problem of social loss, the failure to exploit a potential net social gain (Pareto improvement), disappears in the case of a perfectly-discriminating monopolist, where the owner can charge each consumer his/her full marginal valuation of the copy and, thereby, extract the entire consumer surplus while producing $Q_{C}$. Price discrimination is thus a potential "solution" to the problem to the extent that it can be accomplished (Liebowitz, 1986). ${ }^{9}$ For example, if a way can be found to monitor the use of restricted movie DVDs and charge for usage (much in the same way that one pays for electricity), the problem of underproduction would tend to disappear and more consumers would get to see movies on DVDs. ${ }^{10}$
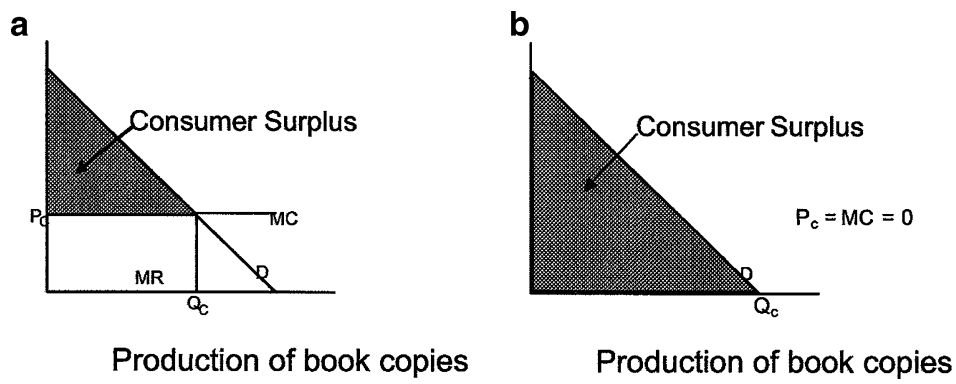

Figure 1. Production of book copies.

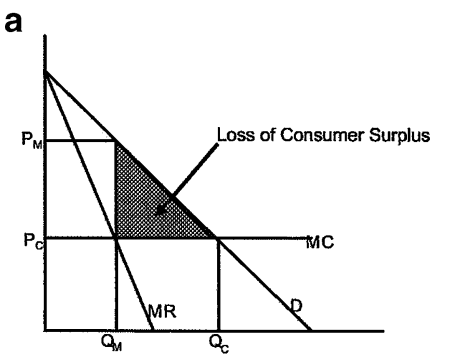

Production of book copies

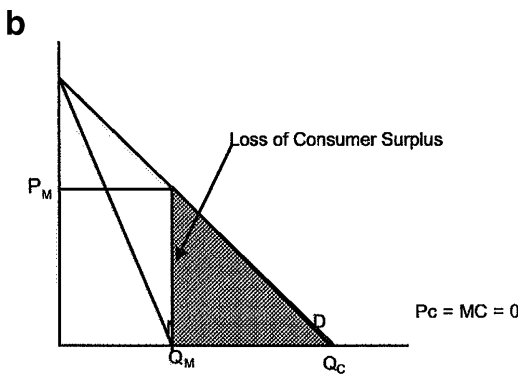

Production of book copies

Figure 2. Production of book copies. 
This framework allows us to pursue many other aspects of IP. It suggests a perspective that sees IP legal systems as a balancing of trade-offs. Take the case of the commercial novel, just considered. The marginal cost of reproducing a novel is likely very low, in the case of a digital copy very close to zero. If the author has copyright she will charge a price for copies well above the marginal cost thereby inflicting a deadweight loss on society, as explained above. However, in the absence of copyright the novel may not have been produced at all. So the deadweight-loss can arguably be seen as a necessary cost for the production of the novel (Liebowitz and Margolis, 2005). In fact, although the marginal-cost of reproduction of the book may be close to zero once the book is produced, from the perspective of the point in time when the book has yet to be produced, this is misleading. Before the book is produced, the marginal-cost of producing another book (another creative work) is decidedly positive. As always, marginal analysis depends crucially on the margin at which the analysis occurs. These considerations are, of course, highly relevant to the case of pharmaceutical drugs, where, once discovered to be beneficial, the reproduction of a drug may cost very little, while the upfront costs of research, discovery and development are enormous. Without the incentive to develop such drugs many fewer may be developed.

In addition, however, we may identify the loss of value that occurs because use is not authorized for complementary products, like derivative works (movies, audio tapes, cartoons, sequels, etc.). Creative artists are continually using IP in the publicdomain for the production of their work. How much of value would not have been produced if a copyright on the works of Shakespeare existed? (Landes and Posner, 2003; Poser 2005a, b). Call this the loss of complementary value (LCV).

Much discussion in this context concerns the question of the establishment of alternative incentive systems for the author (publisher) that does not entail the deadweight loss and, therefore, loss of complementary value. An example is the public subsidization of authors and creators for producing artistic endeavors, thus relieving them of the need for revenue. But these alternatives necessarily involve tax subsidy schemes that have there own "deadweight losses" and clearly restrict individual freedom. In addition, they suffer from all of the well-known knowledge and incentive problems of such public programs, such as the problem of knowing just how much compensation any artist should receive to induce him to produce something, the value of which really cannot be known before time, this being more problematic the more innovative the intellectual product being created. It is a species of the attempt to apply static efficiency criteria to a dynamic context discussed earlier. And, of course, there are the ubiquitous public-choice, rent-seeking problems that will arise as public officials have to be relied upon to implement the policy program in the public interest an not in their own, or their supporters', interests.

These considerations have encouraged those using this Posnerian approach to conclude that the deadweight loss of the copyright system may well be simply a necessary cost of its manifold benefits, the latter being the encouragement of a rich and diverse world of artistic and innovative creations. There is, however, a problem similar to the public-choice problem just mentioned, that is the problem of the length of the patent or copyright. Take the case of copyright; the optimal length for any copyright is that length which is necessary to provide revenue just sufficient to induce the author to produce the work. Anything longer than this would impose deadweight losses greater than is necessary, and anything shorter will result in the work not being produced. The information requirements of actually implementing such a calculation and setting the optimal length of any copyright are prohibitive. It is widely agreed that there no way to obtain all or even most of the necessary information (Landes and Posner, 2003; Liebowitz, forthcoming; Posner, 2005a, b; Varian, 2005). In addition, there is no way to set a different copyright length for each work - or patent length for each invention. The system is unavoidably imperfect as judged within this framework.

But, after all, this is an imperfect world, and in the final analysis, one cannot avoid an appeal to the perceived consequences of any actual, not ideal, IPregime. This is all the more difficult and yet important in the light of modern technological developments. 


\section{Part three - technology and IP}

\section{Locks and keys}

The advent of the internet, and the digital technology that underlies it, has challenged existing ways of thinking about IP. Merely to look at a document on the internet is to "make a copy." The ability to very cheaply copy digital music files (and soon digital video (movie) files) has threatened to completely transform, if not annihilate, established industries, like the music-recording and the motion-picture industries (Liebowitz, 2004). ${ }^{11}$ The former has been involved in some high profile law-suits recently and finds itself potentially at war with many of its customers who routinely download and share music files.

Technology has threatened the status quo in which an uneasy balance existed between allowing routine "fair use" copying, a ban on which is prohibitively expensive to enforce, and banning wholesale commercial copying without license, which has been vigorously enforced. Routine-users now threaten to become routine-copiers who obtain their music and movies for free from the internet rather than purchasing or renting them from the stores or in the theatres. What will this mean for the recording and movie industries? Will artists stop producing? Are there alternative ways to compensate them sufficiently? Will technology develop ways to more cheaply protect these revenues? What is the ethical status of such technologies and technologies to defeat them? This is the stuff of the modem debate.

Perhaps the most accessible starting point is a consideration of the contractual implications of these technologies. Matters would surely be much simpler if "technological locks" could be developed (encryption is a case in point) to safeguard the intellectual property of musicians and moviemakers. These locks act by preventing purchasers of the products embodying this property from copying it. If such a system were effective it would, in effect, be a simple private property system, no different from any other. Anyone purchasing these products could be made aware of the locks existing in them and be presumed to have contractually agreed to them as a condition of sale.
Current technologies go a long way toward meeting these conditions. Encryption, and other locks, on CDs and, especially, DVDs are pretty effective in preventing routine-copying. (The "problem" of the huge volume of already existing digital music files in the public-domain is, of course, not addressed by this, but it would appear to be a potential solution going forward). This is a species of digital-rights management (see Liebowitz, 2002, chapter 7). Other conceivable systems could exist, for example for monitoring use of music or videos and billing accordingly, though such technologies are much less fully developed at this stage.

The concept of digital-rights-anagement is being challenged by some as illegitimate on its face, but it is hard to see how, insofar as these intellectual products come embedded in physical products like CDs, one could object to privately fashioned contractual agreements and obligations. The real problem concerns technologies designed to defeat such technological locks. What should one do for example about devices specifically designed to crack proprietary encryptions on music or other IP? There are those who maintain that, since IP itself is an illegitimate, state-created category, no crime can be attached to such devices. Furthermore, insofar as the CDs, DVDs or any other items embodying IP, are owned by the individuals who bought them, they should be free to do with them whatever they wish - short of coercing others. One could argue perhaps that they can be presumed to have agreed not to try to dismantle the technological locks, but then one is simply back at the thorny enforcement problem the technological lock was supposed to avoid.

Should one prosecute the producers of these "technological keys" instead on grounds that they are accessories to a theft (in the same way one would prosecute the producer of devices designed exclusively for burglars)? Even if one could prove exclusivity of such use, is this a defensible policy? Even if it is, is it practicable, and would it entail generally unacceptable intrusions into private life?

These are difficult questions that are made more difficult by the fact that the technologies are still evolving. The matter would appear less urgent and less relevant if one could feel secure in expectation that common-sense and public-spiritedness would result in the development of temperate and sensible common-law solutions. The dangers I perceive lie in 
two areas - one, in the use of alternative schemes for guaranteeing revenue to creative artists and, two, in overreaching by rent-seekers.

\section{Dangers that lie ahead}

I would claim that the new IP technologies lead us to the conclusion that general enforcement of IP rights in the face of file-sharing and similar technologies, is impossible (and the effort intrusive and undesirable). Some alternatives have been suggested for preserving additional revenue sources. These generally take the form of tax-licensing schemes. One proposal, for example, envisages requiring recording companies to make recordings available for purchase at a fixed price, while taxing the sale of ancillary (complementary) products like CD recordings or blank CDs, pooling the tax revenues and distributing them, according to some formula, to the recording artists. A detailed evaluation of such schemes is beyond he scope of this paper. I will merely assert - in addition to having already noted that they introduce efficiency "distortions" - that they involve highly uncertain and very far-reaching effects that make them extremely unattractive and, more important, open to abuse (for such an examination and overview see Liebowitz, 2003).

This brings up the second danger alluded to above - that of rent-seeking. In truth, the IP area is already seriously plagued by the specter of wasteful and inhibiting special-interest-sponsored legislation and regulation. The area of patent law is a multi billion dollar "club" that arguably inflicts large deadweight losses on an unsuspecting public. In fact, the internet, and computer technology generally, has blurred the line between copyright and patent with most unfortunate consequences. Large-scale rent-seeking by patent lawyers seeking to patent everything from software products (which they treat as business innovations) to business-methods (for an extensive analysis see Jaffe and Lerner, 2004). Current inclinations threaten to lock up many of the fast-arriving innovations and their spin-offs and to deter the creation of others.

Since its origin, copyright law has been amended a few times to extend the term of copyright, not only for new works, but retroactively, in a manner that can only be understood to serve the interests of established copyright holders like Disney who perceive large potential losses to them were their IP to enter the public-domain (but see Liebowitz and Margolis, 2005, who discern some possible economic-efficiency defense for retroactive, expansion). Lawrence Lessig (and others) in numerous recent works (for example, Lessig, 2002; 2004; see also Fisher, 2004; and Vaidhyanathan, 2003) has suggested that these considerations pose grave dangers to the freedom and creativity of our society. $\mathrm{He}$ points out numerous examples of important technological developments and artistic achievements that owe their existence to "free culture" the presence in the public-domain of numerous and varied items of value. "[I]t is a special genius of a common-law system, as ours is, that the law adjusts to the technologies of the time. And as it adjusts, it changes" Lessig, 2004, p. 3). But;

For the first time in our tradition, the ordinary ways in which individuals create and share culture fall within the reach of the regulation of the law, which has expanded to draw within its control a vast amount of culture and creativity that it never reached before. The technology that preserved the balance in our history - between uses of our culture that were free and uses of our culture that were only upon permission - has been undone. (Lessig, 2004, p. 8).

Lessig is here asserting the danger of large losses in complementary value (LCV) discussed earlier. Though articulate in his description of such losses, he is less clear in identifying what should be done about them.

Technology provides the means to both extend and evade control. The perennial danger is familiar, it is that the means to extend control will come to be wielded more and more by big government in the interests of big business, rather than in the interests of any kind of "economic efficiency." It remains to be seen which face of technology will prevail.

\section{Conclusion - a preference for the common law}

This discussion has suggested both the unavoidability and extreme difficulty of applying a Consequentialist ethical approach to IP issues. Custom is of limited 
use in a world where technology is changing rapidly and sometimes radically. Old categories tend to lose their relevance and new ones have to be invented. In such a world, the knowledge and incentive problems that plague conscious legislation are enormous and pose serious dangers to both efficiency and freedom. Though they face many difficulties in this context the courts applying common-law solutions appear to be less threatening in this regard. Our courts seem less susceptible to conflicts of interest and maybe even to uncertainty, having access to local knowledge and expertise on a case-by-case basis. Court decisions that are rendered obsolete by technological developments do not have to be repealed. New circumstances can justify new judicial approaches. All in all I see no preferable alternative to that of leaving vexing questions, like whether to constrain the actions of those who produce technological keys to encrypted proprietary software, to the courts. This I say notwithstanding the current problems created by a specialized patent court of appeals that was created in 1836 (see Jaffe and Lerner, 2004, p. 2; for recommended reforms of the judicial system see chapter 7). ${ }^{12}$ The area of patent law is in serious need of reform, a reform that must rely on the efficiency approach outlined here to redress the loss of balance between creativity and coercion (restraint). But the preference for common law solutions over legislative ones still seems quite compelling in this context. In their deliberations within a rational judicial system judges are more likely than legislators to realize that there really is no alternative to the careful use of basic economic reasoning in the service of discerning the right balance and what place changing elements play in the fabric of the "good society."

\section{Appendix: Are we all Consequentialists now?}

In the text I asserted that all ethics systems come down to some sort of consequentialist argument. This assertion is inspired by the work of Leland Yeager (2001). It seems to me to be particularly relevant to the case of IP. The basic argument is simple. In making pronouncements about the world certain fundamental distinctions apply. First there is David Hume's basic distinction between normative and positive statements -"ought" statements versus "is" statements - and the implication that one can never deduce an ought from an is. One can never deduce a proposition about how things ought to be (what policy ought to be adopted, which type of institutional structure is to be preferred, etc.) exclusively from an observation of how things are. One has to provide a way of evaluating consequences and circumstances. Normative criteria must be combined with positive observations to yield policy prescriptions. "No one can prove in a purely objective way, free of any trace of evaluation or intuition or emotion, that considerateness and kindness are good and that torture and murder are wrong" (Yeager, 2001, p. 18). Crucially, positive observations (investigations into the nature of the natural and social world) are a legitimate part of the policyrecommendation or comparative-systems exercise. And "ethics" is a legitimate part of this inquiry as well. Ethical sensibilities inform what ought to be studied and how the results are to be evaluated and these results in turn may influence such evaluations causing, for example, a change in priorities. There is a two-way relationship between empirical-theoretical investigation and ethical and moral evaluation.

It is this last point that leads to the second type of distinction that needs to be made - that between normative judgments that are fundamental and normative judgments that are specific. The former are more sweeping and inclusive, the latter are less so. Specific value judgments can be seen to rely on, and are instrumental to, more fundamental values; at the highest level fundamental values are not derived from anything. Fundamental normative judgments are thus an expression of a value not derived from any more ultimate value. Logically some values must be fundamental if we are not to proceed in an endless circle where one value depends directly or indirectly on another and the reverse is also true. So, the distinction between fundamental and specific (or instrumental) values would appear to be logically undeniable.

It also clarifies much in the relation that different approaches to the role of ethics in social science, and to property rights in particular, bear to one anotherContractarian, natural-rights, or any other. The basic point is this: whatever criterion one uses as a justifying or motivating cause for a preference or action must be either functioning in the service of some more ultimate value or else must itself be the most ultimate, the last word in the matter. Otherwise in the attempt to seek justification 
one gets either an infinite-regress or a circular argument. "Asking how to validate a value judgment means asking what acknowledged higher norm it falls under" (Yeager, 2001, p. 28). Understanding this suggests a search for the most ultimate value. But clearly this search cannot be informed by reason or by induction (again in line with Hume). "The closest one can come to arguing for a fundamental value judgment is to employ effective rhetoric in identifying an intuition that one expects one's listeners to share" (Yeager, 2001, p. 30).

Yeager suggests that in this context all roads lead back to some perception of what constitutes the "good life" for the individual, and would include evocative words like "flourishing," "peace," and of course, that most serviceable of all words, "happiness." The happiness-criterion would seem to be the most ultimate of criteria. If it is not, then some other word will simply have to be substituted for what it is that stands behind (or above) all other ethical criteria and eventually an end must be found. This applies to all justification systems be it the assertion that societies ought to be organized by the kind of implicit consensus to be found in a "social contract" (how does one know what hypothetically would/should be agreed to? Is it that which would make the people happy? So we are back to consequences.); or by the discernment and exercise of "natural-rights" (which rights are those?; how does one know which rights are "intrinsic"?; are they those that serve "human happiness"? So we are again back to consequences.); or by the discovery and interpretation of the "word of God," or by any other set of criteria. In this he claims to be an indirect-utilitarian. All normative arguments ultimately come down to some criterion like happiness or utility broadly conceived. All arguments come down to the support of or opposition to policies and actions on the basis of how they contribute to or detract from one's conception of what constitutes the "good society." In this sense all such arguments are and must be Consequentialist. And recognizing and acknowledging this leads to better research and policy discussion.

For one thing it suggests (echoing a theme of Milton Friedman's, 1953) that all apparent disagreements ought to be considered potentially resolvable until it can be shown that there is a real difference in fundamental values. As mentioned earlier, it is no use arguing with someone who believes in "evil" or is a pure narcissist, but in many cases apparent disagreements could be resolved if agreement in the fundamentals or nearfundamentals ("we both want prosperity and security for our citizens") could be uncovered and the argument turned to the question of how best to achieve these shared goals. "In real life, disputes over courses of action almost never hinge on divergent ultimate intuitions about intrinsic value" (Yeager, 2001, p. 32).

Ultimate values are by definition, not influenced by states of the world, but instrumental values may be. That is to say (as intimated above) factual knowledge about how the world is can never influence what one feels about the ultimate good, but it can influence one's opinion about how it ought to be achieved. In economic terminology, factual knowledge may help clarify the trade-offs involved and help us choose between instrumental values. "People do not automatically understand all the probable consequences of contemplated changes in policy. They do not fully understand how particular measures may eventually change the general character of their society" (Yeager, 2001, p. 33).

Yeager's argument is a species of rule-utilitarianism, as opposed to act-utilitarianism, so as to rule out exclusive consideration of the utility attached to single acts. Acts must be considered in the context of the time and place that they occur with an eye to their relationship to other acts past and future. Trade-offs may have to be made but they cannot avoid appealing to some notion of what is best for the achievement of social cooperation.

Thus, in appraising alternative legal systems, one apparently cannot avoid either articulating what one believes to be the likely effects, the consequences, of choosing the alternatives considered (a positive judgment), or what one believes about the desirability or otherwise of these effects (a normative judgment). The former is influenced by uncertainty relating to the way the world works (including the effects of subjectively held expectations, etc.). But this does not mean that one need avoid (or, indeed, can avoid) entering into policy discussions. It simply means that one must do so with open eyes and not pretend to know what cannot be known. 


\section{Notes}

1 John Rawls's well known approach, "justice as fairness," (Rawls, 1971, 2001) can be classified as a Contractarian approach that implies substantial compromises on individual property ownership.

2 Resnik (2003) discusses a "Libertarian approach" which he identifies with Robert Nozick deriving from the natural-rights identified by John Locke. In truth, libertarians (classical liberals), modern and past, are found in all three of the approaches identified above, and, moreover, they can be found on both sides of the intellectual-property debate as I hope to have shown in this paper.

3 There is no way, for example, of applying the traditional utility calculus to choices among technologies that are not known and are not yet available.

4 Copyright covers the expression of ideas (for example, through words or music). A copyright currently lasts the duration of the author's lifetime plus 70 years. It provides for narrow protection. It refers to exact matches and coincidental creation of the same product (though very unlikely) is not covered. Copyright is granted without any effort on the part of the creator, and without any test of originality or quality.

Patents, by contrast, last for 20 years. They provide broad protection. If someone else independently creates a duplicate of your invention, after yours has been patented, your patent can make his invention worthless, since he will not have the legal right to sell his application of it. Even close substitutes may be protected. For this reason being first to patent is important and "patent-races" are a predictable and wasteful side-effect of this system. Unlike copyright, obtaining a patent from the patent-office requires the expenditure of considerable resources and the overcoming of multiple legal hurdles relating to originality and quality (see Liebowitz, 2006).

Trade-marks, which must also be registered, but require less onerous procedures, and trade secrets, which require substantial private protection effort on the part of the owner to qualify for legal protection, are also instances of valuable legal titles.

The laws of patents, copyrights and other IP are very complex. The reader should understand this as the simplest of summaries.

5 Such non-pecuniary elements are a large part of the equation in the case of academic publications for example, as are the indirect pecuniary effects related to likelihood of promotion.
6 Something may not have a legal title attached to it, yet still be under the practical control of someone in a way that prevents the use of it by others. I am considering here situations where the title is necessary for its private control. Where it is not necessary the problem is much simplified as discussed below.

7 "The reason why intellectual properties are nonexclusive is that information and ideas have no particular location in time and space: they are abstract objects." (Resnik, 2003, p. 321).

8 It is interesting to note, that the defenders of a natural rights approach inevitably fall parenthetically into a utilitarian mode when they assert, for example, that property protections are unnecessary as incentives to the creation of artistic works and inventions. (We consider this assertion below.) From their point of view, of course, this should be irrelevant.

9 From a Coasian perspective it is a way of moving off the Pareto-inefficient position through negotiation. But when the transactions costs of implementing it are prohibitive it is not a solution.

10 In the absence of legal property rights there are often "indirect ways" to appropriate the value of the asset - for example, by changing a higher price for a strictly complementary non-IP good or service (the price of CD's rising to compensate for an inability to charge for much of the software that is copied to CD's without payment). This is necessarily an imperfect solution, and is the basis for suggesting a tax on CD's to compensate the creators of software. It should also be noted that sometimes "free" goods are complements for their purchased cousins, as when consumers download songs in order to sample the album with a view to purchase. These "exposure" effects soften the incentive problems of the public goods aspects of IP. But it is no small matter to discern their magnitude (see Liebowitz, 2002, chapter 7).

11 It has now been pretty well established that filesharing constitutes a credible threat to the revenue sources of the music industry though the magnitude is less clear (Liebowitz, 2005).

12 Jaffe and Lerner propose a number of reforms among which is the replacement of juries by judges in patent cases, and the creation of multiple levels of review. The general thrust of their proposals would make patents more difficult to get and to defend against challenges and this would provide less incentive for "frivolous patenting," thus reducing deadweight-losses and actually encouraging truly creative contributions (Jaffe and Lerner, 2004, chapter 7). 


\section{Acknowledgements}

An early version of this paper was presented at the Southern Economic Association meetings in Washington D.C. in November 2005. I am very grateful to the audience for a lively discussion and to Howard Baetjer and Sudha Shenoy for very helpful comments. I am also greatly indebted to Stan Liebowitz for helpful discussions and for reading the manuscript and providing very useful suggestions. The usual disclaimer applies. Financial assistance in the form of a research grant from the Center for the Analysis of Property Rights and Innovation, at the School of Management of University of Texas at Dallas, is very gratefully acknowledged.

\section{References}

Buchanan, J. M.: 1977, The Limits of Liberty: Between Anarchy and Leviathan (University of Chicago Press, Chicago).

Fisher, W. W., III: 2004, Promises to Keep: Technology, Law and the Future of Entertainment (Stanford University Press, Palo Alto).

Friedman, M.: 1953, The Methodology of Positive Economics' in Essays on Positive Economics (University of Chicago Press, Chicago).

Gordon, W. J.: 1993, 'Property Right in Self Expression: Equality and Individualism in the Natural Law of Intellectual Property', Yale Law Journal 102, 1533.

Hegel, F.: 1976 [1821], The Philosophy of the Right, Knox, T. (trans.) (Oxford University Press, Oxford).

Jaffe, A. B. and J. Lerner: 2004, Innovation and Its Discontents: How our Broken Patent System is Endangering Innovation and Progress, and What to Do About It (Princeton University Press, Princeton, NJ).

Kinsella, N. S.: 2001, 'Against Intellectual Property', Journal Libertarian Studies 15((2), 1-53.

Landes, W. M. and R. A. Posner: 2003, The Economic Structure of Intellectual Property Law (Harvard University Press, Cambridge).

Lewin, P.: 1982, 'Externalities: Social Cost Versus Strict Liability', CATO Journal 2(1), 205-229.

Lessig, L.: 2002, The Future of Ideas (Random House, New York).

Lessig, L.: 2004, Free Culture (The Penguin Press, New York).

Liebowitz S. J.: 1986, 'Copyright Law, Photocopying and Price Discrimination', Research in Law and Economics 181-200.
Liebowitz, S. J.: 2002, Re-Thinking the Network Economy: The True Forces that Drive the Digital Marketplace (Amacom, New York).

Liebowitz S. J.: 2003, Alternative Copy Systems: The Problems with a Compulsory License', IPCentral Review 12 May http://www.ipcentral.info/review/ vln2intro.html.

Liebowitz, S. J.: 2004, 'Will MP3 Downloads Annihilate the Record Industry? The Evidence so Far", Advances in the Study of Entrepreneurship, Innovation, and Economic Growth 15, 229-260.

Liebowitz, S. J.: 2005, 'Pitfalls in the Analysis of FileSharing', CESInfo Economic Studies 51(23), 439-447.

Liebowitz S. J.: (forthcoming) 'Intellectual Property', The Concise Encyclopedia of Economics http://www.econlib.org/library/CEE.html.

Liebowitz, S. J. and S. Margolis: 2005, 'Seventeen Famous Economists Weigh in on Copyright: The Role of Theory, Empirics, and Network Effects', Harvard Journal of Law and Technology 18(2), 435457.

Nozick, R.: 1977, Anarchy, State and Utopia (Basic Books, New York).

Palmer, T. G.: 1989, 'Intellectual Property: A NonPosnerian Law and Economics Approach', Hamline Law Review 12(2), 261-304.

Palmer, T. G.: 1990, 'Are Patents and Copyrights Morally Justified? The Philosophy of Property Rights and Ideal Objects', Harvard Journal of Law and Public Policy 13 ((3), 817-865.

Plant, A.: 1934a, 'The Economics Theory Concerning Patents for Inventions' Economica', New Series 11, 30-51.

Plant, A.: 1934b, 'The Economic Aspects of Copyright in Books', Economica, New Series 12, 167-195.

Posner, R. A.: 2005a, 'Intellectual Property: The Law and Economics Approach', Journal of Economic Perspectives 19(2), 57-73.

Posner, R. A.: 2005b, 'Hayek, Law, and Cognition', NYU Journal of Law and Liberty 1, 147-165.

Rawls, J.: 1971, A Theory of Justice (Belknap Press, New York).

Rawls, J.: 2001, Justice as Fairness (Belknap Press, New York).

Resnik, D. B.: 2003, 'A Pluralistic Account of Intellectual Property', Journal of Business Ethics 46, 319-335.

Spooner, L.: 1971, 'The Law of Intellectual Property: Or An Essay on the Right of Authors and Inventors to a Perpetual Property in Their Ideas' in The Collected Works of Lysander Spooner C Shively ed. 3 (M\&S Press, Weston, Mass). 
Stringham, E.: 2001, 'Kaldor-Hicks Efficiency and the

Peter Lewin Problem of Central Planning', Quarterly Journal of Austrian Economics 4(2), 41-50.

Vaidhyanathan, S.: 2003, Copyrights and Copywrongs: The Rise of Intellectual Property and How It Threatens Creativity (New York University Press, New York).

Varian, H. R.: 2005, 'Copying and Copyright', Journal of Economic Perspectives 19(2), 121-138.

Yeager, L. B.: 2001, Ethics as Social Science: The Moral Philosophy of Social Cooperation (Edward Elgar, Northampton).

School of Management, University of Texas at Dallas, SM 31, PO Box 830688, Richardson, TX 75083-0688,

U.S.A.

Email: plewin@utdallas.edu 